\title{
Three-portal technique for anterior cruciate ligament reconstruction: Use of a central medial portal
}

\author{
Steven B. Cohen \\ Thomas Jefferson University \\ Freddie $\mathrm{H}$. Fu \\ University of Pittsburgh
}

Follow this and additional works at: https://jdc.jefferson.edu/orthofp

Part of the Orthopedics Commons

Let us know how access to this document benefits you

\section{Recommended Citation}

Cohen, Steven B. and Fu, Freddie H., "Three-portal technique for anterior cruciate ligament reconstruction: Use of a central medial portal" (2007). Department of Orthopaedic Surgery Faculty Papers. Paper 11.

https://jdc.jefferson.edu/orthofp/11

This Article is brought to you for free and open access by the Jefferson Digital Commons. The Jefferson Digital Commons is a service of Thomas Jefferson University's Center for Teaching and Learning (CTL). The Commons is a showcase for Jefferson books and journals, peer-reviewed scholarly publications, unique historical collections from the University archives, and teaching tools. The Jefferson Digital Commons allows researchers and interested readers anywhere in the world to learn about and keep up to date with Jefferson scholarship. This article has been accepted for inclusion in Department of Orthopaedic Surgery Faculty Papers by an authorized administrator of the Jefferson Digital Commons. For more information, please contact: JeffersonDigitalCommons@jefferson.edu. 
From the University of Pittsburgh Center for Sports Medicine, Pittsburgh, PA

Corresponding author:

Freddie H. Fu, MD, DSc, DPs (Hon)

Center for Sports Medicine

University of Pittsburgh Medical Center

3200 S. Water Street

Pittsburgh, PA 15203

ffu@upmc.edu

412-432-3662

46 Fax: 412-432-3690 


\section{Introduction}

48 Traditional endoscopic anterior cruciate ligament (ACL) reconstruction is

49 performed using two standard portals. The anterolateral portal is used as the viewing

50 portal and the anteromedial portal is used as the working portal. When performing ACL

51 reconstruction however the posterior aspect of the lateral intercondylar notch may be

52 difficult to view entirely through the lateral portal. There have been numerous

53 descriptions for portal locations for knee arthroscopy, but no article has noted optimal

54 locations for specific portals relating to ACL reconstruction.[1-6] In fact, Kurosaka has

55 used a similar multiple portal technique for ACL reconstruction for several years

56 [personal communication, 2002].

57 Conventionally, the anterolateral portal is positioned above the joint line just

58 lateral to the lateral border of the patella tendon. Likewise, the anteromedial portal can

59 be created by direct visualization using a spinal needle but is located slightly above the

60 joint line and just off or nearly $1 \mathrm{~cm}$ medial to the medial border of the patella tendon.

61 From our experience these portals limit anatomic placement of both the tibial and femoral

62 tunnels during ACL reconstruction by preventing proper visualization of both the tibial

63 plateau and lateral wall of the intercondylar notch. Our current technique for endoscopic

64 anatomic double bundle ACL reconstruction, a modification from Kurosaka, has been

65 well described and involves the use of three portals [7, 8], which are used

66 interchangeably as viewing and working portals based on the specific task being

67 performed, much like that of arthroscopy of the shoulder.(Table 1) 


\section{Portal Location}

\section{9 “High” Anterolateral Portal}

70 The anterolateral portal is initially used as the viewing portal. It is located just

71 lateral to the patella tendon with the most inferior portion of the portal at the level of the

72 inferior pole of the patella when the knee is flexed to 60 degrees (Figure 1). The portal

73 is created with an 11-scalpel blade taking care to avoid damage to the articular cartilage

74 when penetrating the capsule. This portal avoids penetration into the fat pad and is used

75 for the diagnostic arthroscopy, as it allows complete viewing of the patellafemoral,

76 medial, and lateral compartments of the knee without significant resection of the fat pad.

77 Additionally, the anterolateral portal is used to determine the precise position of the

78 anteromedial (AM) and posterolateral (PL) bundles of the ACL at its insertion on the

79 tibia. These sites are marked in preparation for drilling the two tibial tunnels for ACL

80 reconstruction (table 2). The superior position of the portal allows a wider view of the

81 tibial insertion of the ACL.

\section{Anteromedial Portal (Central Portal)}

83 The anteromedial or "central" portal is used as a working and a viewing portal. It

84 is placed nearly $1 \mathrm{~cm}$ lateral to the medial border of the patella tendon (intratendinous)

85 just inferior from the inferior pole of the patella when the knee is flexed to 60 degrees

86 (Figure 1). Again, the portal is created with an 11-scalpel blade taking care to avoid the

87 articular cartilage of the trochlea. This portal is specifically used for viewing the wall of

88 the lateral intercondylar notch and marking the insertion sites of the AM and PL bundles

89 of the ACL (Table 2). While viewing through this portal, the accessory medial portal

90 becomes the working portal. By working in this fashion, no "notchplasty" or 
91 "wallplasty" is required because there is no obstruction to viewing the notch, and each

92 bundle is placed in its anatomic insertion while avoiding impingement of the posterior

93 cruciate ligament (PCL). Additionally, the anteromedial portal is used to place the guide

94 (which is set on 45 degrees) for drilling the AM tibial tunnel.

95 Accessory Medial Portal

96 The accessory medial portal is used mainly as the working portal for PL bundle

97 femoral tunnel placement. Nearly $30 \%$ of the time it is also used for AM bundle femoral

98 tunnel placement when the transtibial technique does not allow for anatomic AM femoral

99 tunnel drilling. The portal is created using direct visualization with a 18-gauge spinal

100 needle typically just superior to the medial joint line approximately $2 \mathrm{~cm}$ medial to the

101 medial border of the patella tendon (Figure $1 \& 2$ ). This allows the proper angle to drill

102 the PL (and if necessary the AM) femoral tunnel with avoidance of injury to the cartilage

103 of the medial femoral condyle. It is also used to place the guide (which is set on 55

104 degrees) for the PL bundle tibial tunnel. By placing the guide in different portals for the

105 AM and PL tunnels in the tibia, this allows for a larger bone bridge and the proper angle

106 for tunnel placement (Table 2). In addition, the accessory medial portal may be used as

107 a viewing portal to view the femoral insertion of the ACL in the notch.

108 Discussion

109 In shoulder arthroscopy, multiple portals are used to perform specific tasks.

110 Similarly, arthroscopy of the knee and more specifically ACL reconstruction, portal

111 placement is critical to successfully perform the intended procedure. Each of the three

112 portals described above have specific roles during surgery (Figure 3). It is crucial to

113 visualize the ACL footprint on the tibia to determine the precise anatomic location of the 
114 AM and PL bundles of the ACL for tibial tunnel placement (Figure 4). Likewise,

115 viewing the lateral aspect of the intercondylar notch through the standard lateral portal

116 without a notchplasty to define the anatomic femoral insertion of the ACL can be quite

117 limited (Figure 5). This may cause nonanatomic femoral tunnel placement during single

118 or double bundle reconstruction. As a result, we recommend the use of the medial portal

119 as the viewing portal for femoral tunnel drilling and the use of an accessory medial

120 working portal. This prevents the need for removal of any bone from the notch.

121 During anatomic double bundle ACL reconstruction, it is helpful to use a variety

122 of portals throughout the surgery. For marking the anatomic insertions of the ACL on the

123 tibia and tibial tunnel drilling, we recommend using the "high" lateral portal for its

124 greatest visualization of the tibial footprint. Contrary to traditional ACL reconstruction,

125 we advocate using the anteromedial (middle) viewing portal to determine the femoral

126 origin of the AM and PL bundles of the ACL on the femur. In order to do this, the

127 accessory medial portal is used as a working portal for drilling the PL femoral tunnel and

128 if necessary the AM femoral tunnel. Most commonly, the AM femoral tunnel can be

129 placed with the transtibial technique, however if the transtibial technique places the AM

130 tunnel too vertical or non-anatomic, the accessory medial portal is used to drill the AM

131 femoral tunnel.

132 The most common complication associated with ACL reconstruction is erroneous

133 tunnel placement.[9] The are a variety of causes of this, but poor visualization of the

134 anatomic landmarks is will likely cause inaccurate tunnel placement. We propose the

135 solution to poor intercondylar notch visualization is not notchplasty or wallplasty but

136 rather altering the viewing location and adding an accessory medial working portal. This 
137 will allow improved visualization of both tibial and femoral anatomic insertions of the

138 ACL and may prevent improper tunnel position during ACL reconstruction.

139

140 


\section{References}

1. Dandy DJ. Basic technique: The standard approach. In: McGinty JB, ed. Operative Arthroscopy. Philadelphia: Lippincott-Raven, 1996;243:252-253.

2. Eriksson E, Sebik A. A comparison between the transpatellar tendon and lateral approach to the knee joint during arthroscopy: A cadaveric study. Am J Sports Med 1980;8:103.

3. Kim SJ, Kim HJ. High portal: Practical philosophy for positioning portals in knee arthroscopy. Arthroscopy 2001;17:333-337.

4. Ong BC, Shen FH, Musahl V, Fu FH, Diduch DR. Knee: Patient positioning, portal placement, and normal arthroscopic anatomy. In: Miller MD, Cole BJ, eds. Textbook of Arthroscopy. Philadelphia: Elsevier, 2004;46:463-469.

5. Parisien JS. Normal arthroscopic anatomy, portals, and techniques. Presented at the $62^{\text {nd }}$ Annual meeting of the American Academy of Orthopaedic Surgeons, Feb 1995; Orlando, FL.

6. Stetson WB, Templin K. Two-versus three-portal technique for routine knee arthroscopy. Am J Sports Med 2002;30:108-111.

7. Cohen SB, Starman J, Fu FH. Anatomic double bundle anterior cruciate ligament reconstruction. Tech Knee Surg. In press.

8. Zelle B, Brucker PU, Feng MT, Fu FH. Anatomical double-bundle anterior cruciate ligament reconstruction. Sports Med 2006;36:99-108.

9. Sommer C, Friederich NF, Muller W. Improperly placed anterior cruciate ligament grafts: correlation between radiological parameters and clinical results. Knee Surg Sports Traumatol Arthrosc 2000;8(4):207-13. 


\section{Figures}

166

167

168 Figure 1: Portal locations marked on skin for ACL reconstruction

169

170

171

172

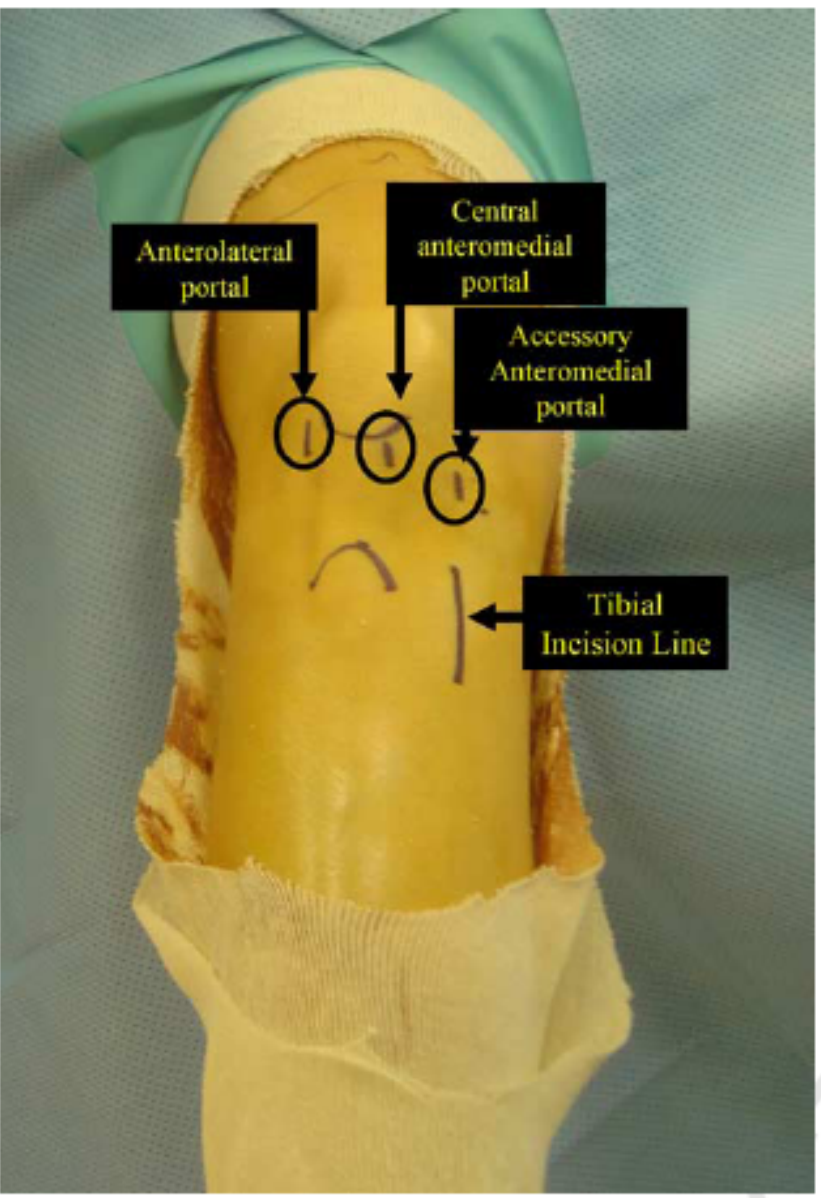


174 Figure 2: External view of arthroscopic instruments during ACL reconstruction. A)

175 Scope in the anterolateral portal and a spinal needle used to identify location of the

176 accessory medial portal in a right knee, B) Scope in anteromedial portal and guide-pin

177 placed in the accessory medial portal for placement of the posterolateral bundle tunnel in 178 the femur of the left knee

179
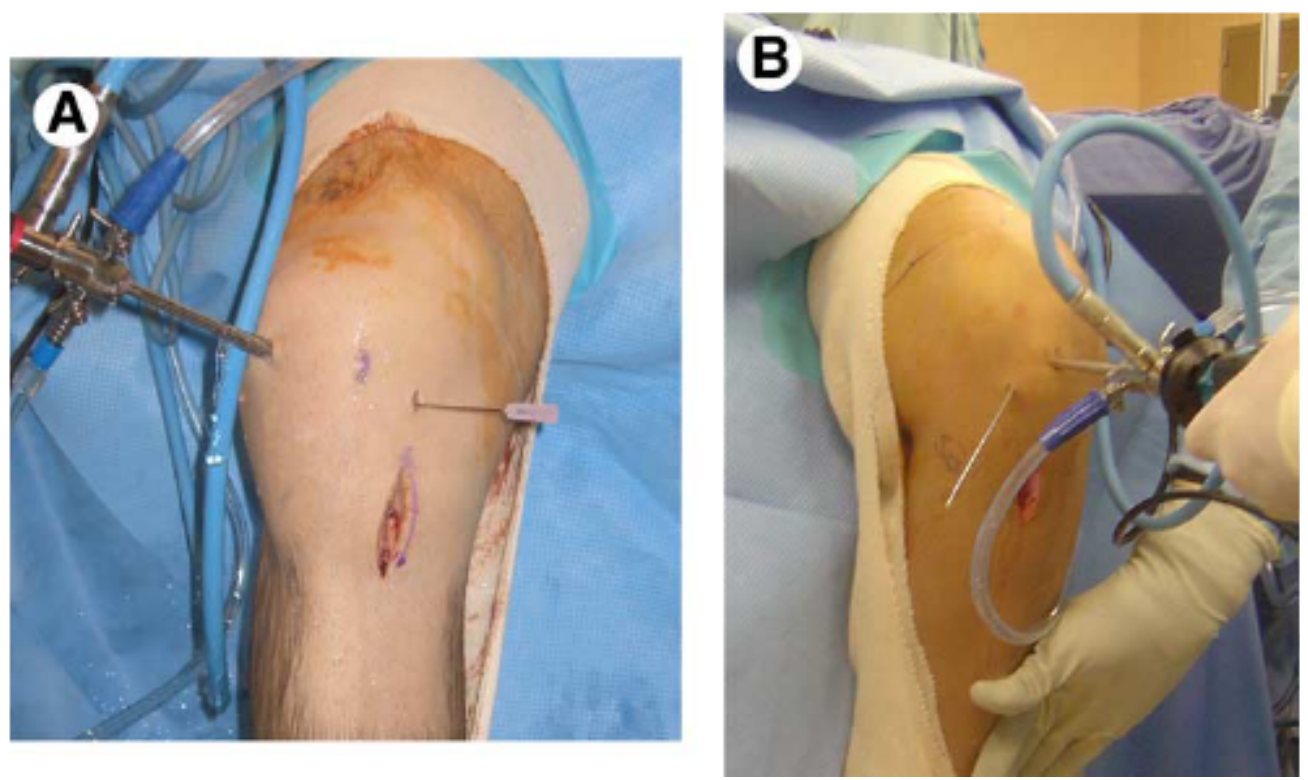

181 
183 Figure 3: Arthroscopic view of the intercondylar notch of a right knee from the 184 anterolateral portal (ALP), anteromedial portal (AMP), and accessory medial portal (MP)

\section{Scope in}

CAMP

Scope in

\section{Scope in ALP}

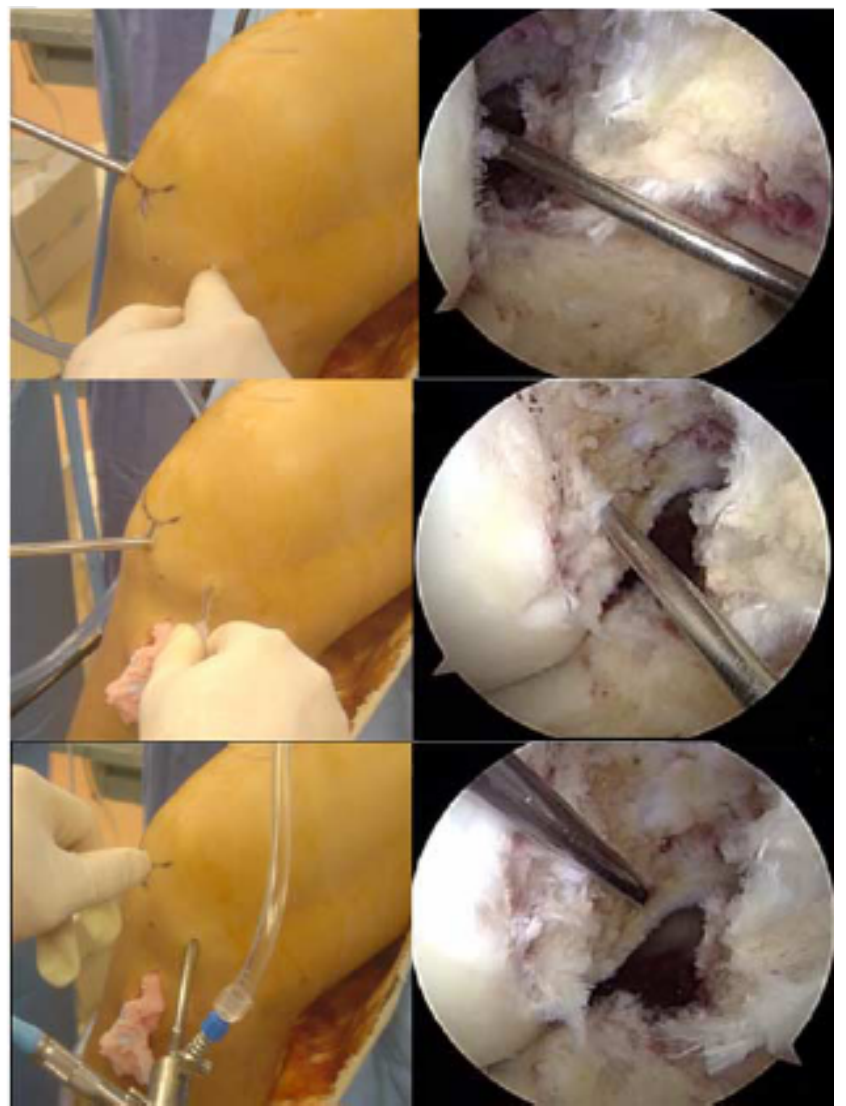
accessory AMP

Figure 4: Arthroscopic view of the tibial plateau of a right knee through the anterolateral portal after placement of the anteromedial and posterolateral bundle tunnels in the tibia

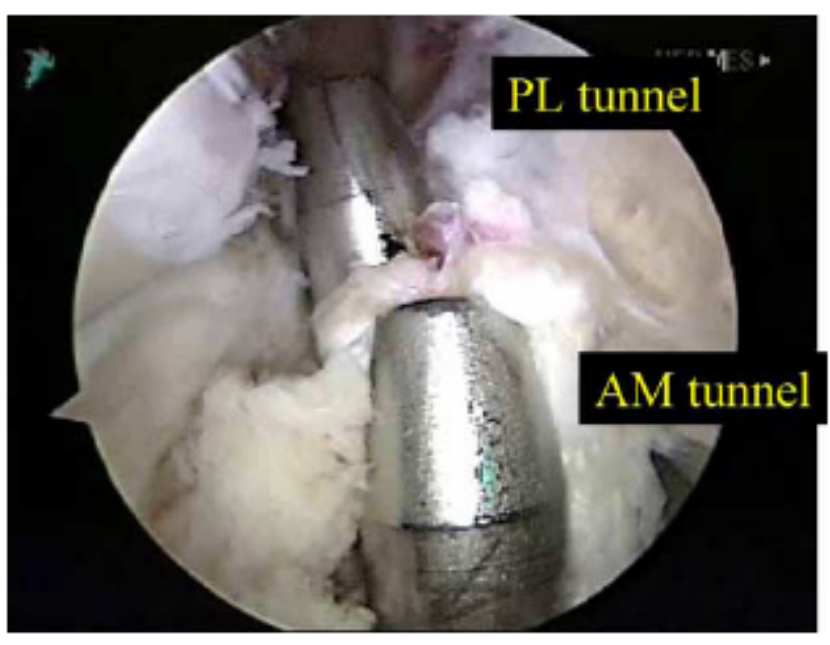


195 Figure 5: Arthroscopic view of the intercondylar notch of a right knee from the

196 anterolateral portal (A) and the anteromedial portal (B) after placement of the 2 femoral tunnels during ACL reconstruction
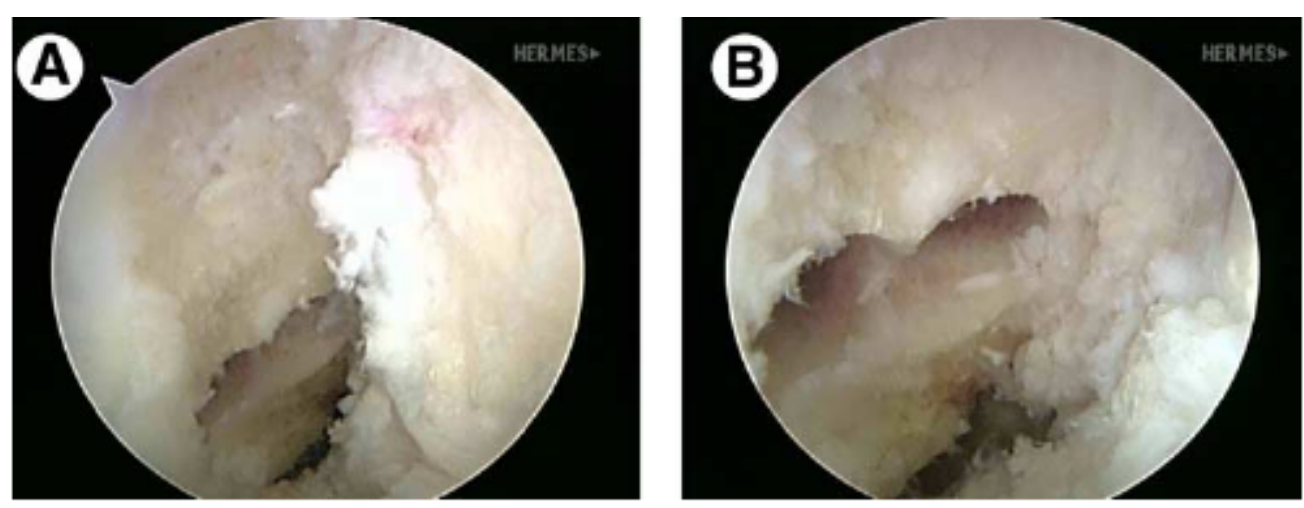

Table 1: Use of portals in anatomic double bundle ACL reconstruction

\begin{tabular}{|l|l|l|l|}
\hline Portal & Viewing Advantage & Surgical Purpose & Working Portal \\
\hline Anterolateral & $\begin{array}{l}\text { Anatomic insertion of } \\
\text { ACL on Tibia }\end{array}$ & $\begin{array}{l}\text { Viewing tibia for } \\
\text { tibial tunnel } \\
\text { placement }\end{array}$ & $\begin{array}{l}\text { Inside-out medial } \\
\text { meniscal repair }\end{array}$ \\
\hline Anteromedial & $\begin{array}{l}\text { Anatomic insertion of } \\
\text { ACL in Intercondylar } \\
\text { Notch }\end{array}$ & $\begin{array}{l}\text { Viewing } \\
\text { intercondylar } \\
\text { notch for femoral } \\
\text { tunnel placement }\end{array}$ & $\begin{array}{l}\text { Tibial guide } \\
\text { placement for } \\
\text { drilling AM tunnel }\end{array}$ \\
\hline Accessory Medial & $\begin{array}{l}\text { Anatomic insertion of } \\
\text { ACL in Intercondylar } \\
\text { Notch }\end{array}$ & $\begin{array}{l}\text { Placement of PL } \\
\text { and if necessary } \\
\text { AM tunnels in } \\
\text { femur }\end{array}$ & $\begin{array}{l}\text { Tibial guide } \\
\text { placement for } \\
\text { drilling PL tunnel }\end{array}$ \\
\hline
\end{tabular}

Table 2: Specific portal use for anatomic double bundle ACL reconstruction

\begin{tabular}{|l|l|l|}
\hline $\begin{array}{l}\text { Tunnel for ACL } \\
\text { Reconstruction }\end{array}$ & Viewing Portal & Instrument Portal \\
\hline Tibia - Anteromedial Bundle & Anterolateral & Anteromedial \\
\hline Tibia - Posterolateral Bundle & Anterolateral & Accessory Medial \\
\hline Femur - Anteromedial Bundle & Anteromedial & $\begin{array}{l}\text { Transtibial or Accessory } \\
\text { Medial }\end{array}$ \\
\hline Femur - Posterolateral Bundle & Anteromedial & Accessory Medial \\
\hline
\end{tabular}

